\title{
Perencanaan Sistem Penerangan Ruangan
}

\author{
Soetjipto Soewono $^{1}$ : $^{\text {Evi Suhaevi }}{ }^{2}$
}

${ }^{1}$ Dosen Program Magister Teknik Ketenagalistrikan dan Energi Sekolah Tinggi Teknik PLN ${ }^{2}$ Mahasiswa Program Magister Teknik Ketenagalistrikan dan Energi Sekolah Tinggi Teknik PLN 2suhaevi_e@yahoo.com

\begin{abstract}
Lighting becomes one of the important factors to support facilities for teaching and learning study. STT PLN building is one of the buildings use as classroom for teaching and learning study that will improve the quality of facilities. Standar lighting in the class room 250 lux base on SNI 03-61972000.Research was conducted in the STT PLN building which was used as a class room. Activities include measuring ligh in class room, measuring the width, height and length of $s$ room by using a meter to determine the distance between armatures in the calss room. The existence of this research is expected to be a solution for class building to Standar National Indonesian (SNI).
\end{abstract}

Keywords: storing light, calss room, standar

\begin{abstract}
ABSTRAK
Penerangan menjadi salah satu faktor penting untuk mendukung sarana dan prasarana dalam kegiatan belajar mengajar. Gedung STT PLN salah satunya gedung yang di gunakan sebagai perkuliahan yang akan meningkatkan kualitas sarana dan prasarana untuk kegiatan belajar mengajar. Seperti di ketahui standar untuk ruang perkuliahan sebesar 250 lux berdasarkan SNI 036197-2000. Pada penelitian ini dilakukan di gedung Sekolah Tinggi Teknik PLN yang dipakai sebagai ruang perkuliahan. Kegiatan yang dilakukan diantaranya pengukuran cahaya pada ruang perkuliahan dengan menggunakan luxmeter, mengukur lebar, tinggi dan panjang ruangan dengan menggunakan meteran guna untuk menentukan jarak antar armatur pada ruangan tersebut. Dengan adanya penelitian ini diharapkan menjadi solusi untuk gedung perkuliahan agar sesuai standar nasional Indonesia pada Penerangannya
\end{abstract}

Kata kunci: Penerangan, ruang kelas, standar 


\section{PENDAHULUAN}

\subsection{Latar Belakang}

Dalam kehidupan sehari-hari kita tidak pernah terlepas dari listrik, salah satunya digunakan sebagai penerangan baik dirumah, di kantor maupun di gedung perkuliahan. Penerangan dijaman sekarang ini menjadi kebutuhan primer, karena semua aktifitas memerlukan penerangan sebagai sarana untuk mempermudah melakukan aktifitas, misalnya diperkantoran tidak lepas dari penerangan yang diigunakan untuk mempermudah pekerjaan, bidang pendidikan di gunakan penerangan untuk mempermudah proses belajar mengajar.

Menurut penelitian yang dapat dihimpun dari penulis Atnam, Zulfahri yang menganalisis pencahayaan dan pengguna energi listrik d laboratorium komputer sekolah dasar negeri 150 Pekanbaru yang hasilnya intensitas Pencahayaan rata-rata di ruangan laboratorium komputer Sekolah Dasar Negeri 150 Pekanbaru untuk tiap titik meja kerja/komputer sebesar 171 lux sehingga intensitas pencahayaan nya masih rendah. [1]

Dihimpun dari penulis Abdul Muis Mappalotteng dan Syahrul yang menganalisis pencahayaan pada ruangan gedung program pacasarjana UNM Makassar yang hasilnya yaitu kondisi pencahayaan alam dengan mengandalkan cahaya matahari pada siang hari telah memenuhi standar sebesar 41,67\%. [2]

Serta di himpun dari penulis Sri Kurniasih yang menganalisis optimasi sistem pencahayaan pada ruang kelas Universitas Budi Luhur luas bukaan berupa jendela sudah memenuhi standar sehingga cahay matahari dapat masuk dengan optimal, dan warna cat dinding kondisi eksisting yaitu whitegrey kurang mampu mendistribusikan cahaya secara merata. [3]

Gedung Sekolah Tinggi Teknik PLN Jakarta salah satu gedung yang digunakan untuk perkuliahan, gedung tersebut terdiri dari 12 lantai dimana lantai 1 sebagai loby, lantai 2 sampai lantai 10 digunakan sebagai ruang perkuliahan, lantai 11 digunakan sebagai ruang kantor atau staff dan lantai 12 dipakai sebagai audiotorium. Gedung tersebut mayoritas di gunakan sebagai kegiatan belajar mengajar sehingga sangat memerlukan penerangan sebagai sarana pendukung dalam proses belajar mengajar. Oleh karena itu di perlukan pengecekan penerangan nya guna meningkatkan kualitas sarana dan prasarana agar lebih baik dan sesuai standar.

\section{METODE/PERANCANGAN PENELITIAN}

\subsection{Lokasi Penelitian}

Lokasi penelitian yang di lakukan di gedung STT PLN, yang mempunyai luas sekitar $400 \mathrm{~m}^{2}$ didalam gedung ini terdapat ruangan yang mayoritas di gunakan sebagai ruang perkuliahan, studi kasus ini di lakukan pada ruang 912 dimana terdapat 12 titik armatur atau kap. Setiap titik armatur seharusnya memiliki 2 lampu, tapi kondisi aktualnya hanya terdiri dari 1 lampu saja. Sehingga dengan adanya penelitian ini dapat menjadi solusi untuk mengoptimalkan jumlah lampu dan armatur dalam ruangan. Gambar dibawah ini merupakan sketsa ruangan yang ada di lantai 9. Yang salah satu ruangan nya akan di jadikan fokus utama untuk mencari jumlah titik armatur serta jarak antar armatur. 


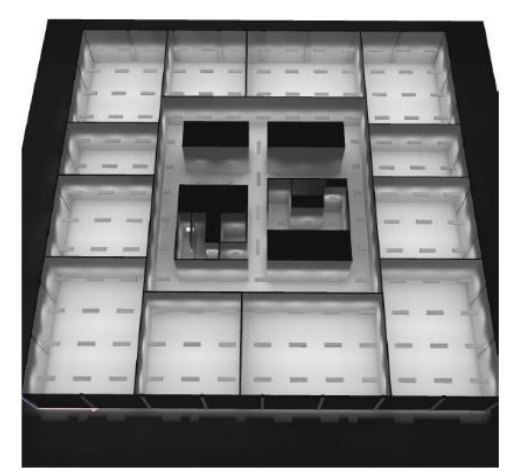

Gambar 1. Sketsa lantai 9

\subsection{Metode Penelitian dan Pengumpulan Data}

Metode penelitian yang digunakan dalam tesis ini adalah metode penelitian kuantitatif dimana metode ini akan digunakan untuk menentukan jarak antar armatur pada lampu yang berada di dalam ruang khususnya untuk ruang perkuliahan pada lantai 9 gedung STT PLN. Dalam penelitian ini akan di lakukan komparasi antara kondisi aktual pencahayaan pada objek yang diteliti dengan standar pencahayaan SNI 03-6197-2000. Untuk mendukung penelitian ini diperlukan metode seperti studi literatur dan studi lapangan.

\subsubsection{Studi Literatur}

Studi literature merupakan hal yang mendasar dari penelitian dengan tujuan mempelajari teori dasar tentang penerangan yang mengambil referensi dari penelitian-penelitian sebelumnya dan mempelajari teori-teori yang relevan dengan penelitian ini yang diambil dari buku, situs internet, dan jurnal ilmiah.

\subsubsection{Studi Lapangan}

Studi lapangan dilakukan di gedung STT PLN dengan mengukur penerangan di ruang perkuliahan, membaca angka hasil pengukuran yang tertera di luxmeter, mengukur panjang ruang kuliah, lebar ruang kuliah serta tinggi dari flapon ke lantai dengan menggunakan meteran.

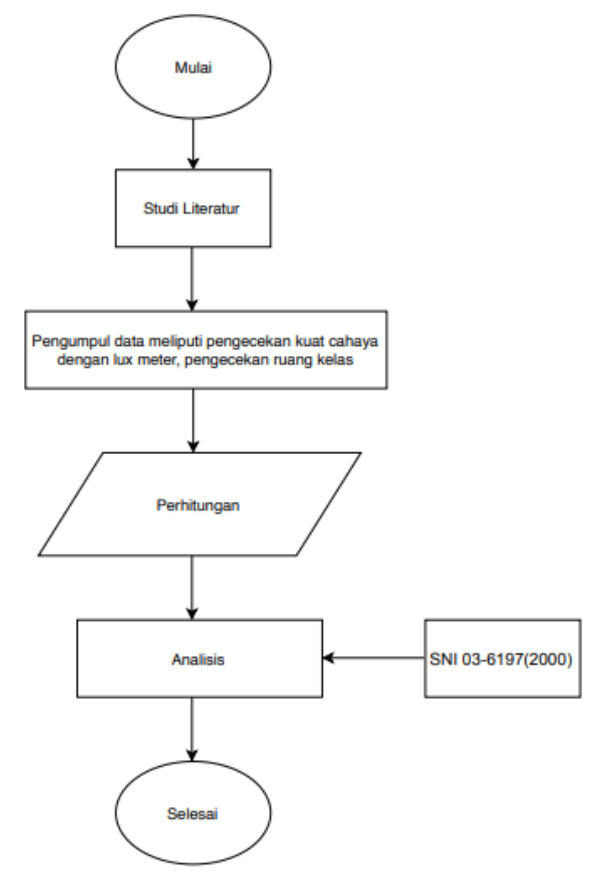

Gambar 2. Alur Penelitian 


\section{HASIL DAN PEMBAHASAN}

Studi kasus pada tesis ini dilakukan di kampus Sekolah Tinggi Teknik PLN data yang diambil meliputi pengukuran cahaya menggunakan lux meter, mengukur panjang, tinggi dan lebar ruangan dengan menggunakan meteran. Lampu yang digunakan merk Philips TL - D 36watt Dalam penelitian ini terdapat pengukuran di waktu siang dan malam hari untuk Penerangan nya, dikarenakan STT PLN akan membuka kelas malam sehingga diperlukan adanya penelitian ini guna untuk mengecek kebutuhan Penerangan nya dapat terpenuhi.

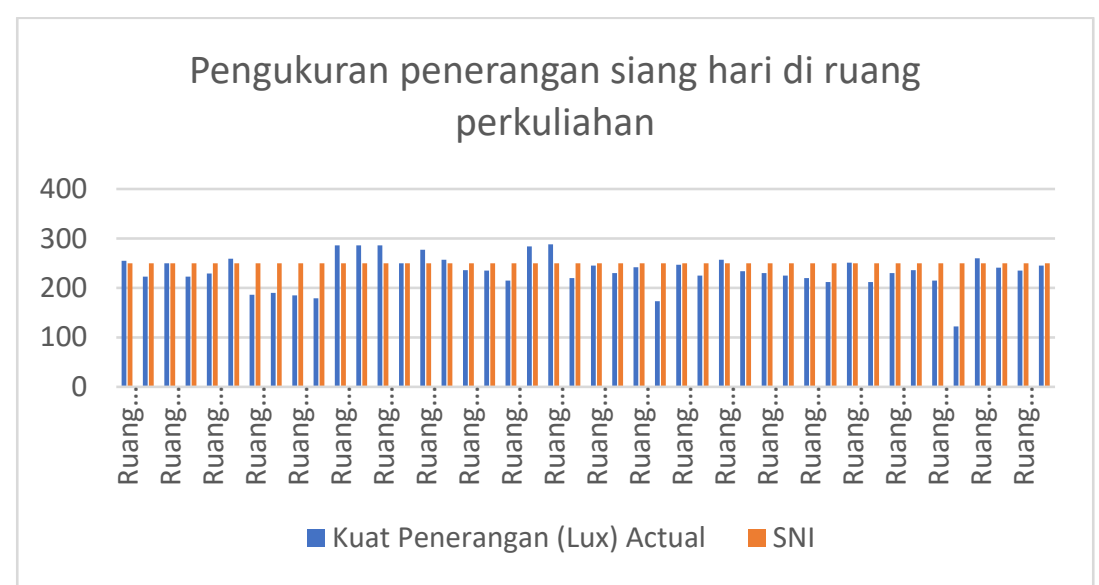

Gambar 3. grafik hasil pengukuran penerangan di ruang kuliah STT PLN

Pada grafik diatas dapat dilihat bahwa penerangan di ruang kuliah STT PLN rata- rata kurang dari 250 lux baik pada malam maupun pada siang hari. Tetapi untuk siang hari hampir mendekati 250 lux dikarenakan adanya bantuan cahaya matahari pada ruangan.

\subsection{Menentukan Rumus Sederhana Untuk Menentukan Titik Armatur Pada Ruangan \\ Parameter \\ Satuan \\ Satuan Dalam (m)}

Panjang Ruangan

Lebar Ruangan

Luas Ruangan

SNI Kuat cahaya ruanga kelas

SNI Kuat cahaya ruang kantor

SNI Kuat cahaya ruang lab

SNI Kuat cahaya ruang Gambar

SNI Kuat cahaya ruang perpus
$1020 \mathrm{~cm}$

$645 \mathrm{~cm}$

$657900 \mathrm{~cm}^{2}$

250 lumen $/ \mathrm{m}^{2}$

350 lumen $/ \mathrm{m}^{2}$

500 lumen $/ \mathrm{m}^{2}$

750 lumen $/ \mathrm{m}^{2}$

300 lumen $/ \mathrm{m}^{2}$
$10,2 \mathrm{~m}$

$6,45 \mathrm{~m}$

$65,79 \mathrm{~m}^{2}$

$250 \operatorname{lux}[4]$

$350 \operatorname{lux}$

$500 \operatorname{lux}$

$750 \operatorname{lux}$

$300 \operatorname{lux}$

Lampu yang di gunakan:

Merk Philips, Type : TL-D 36 watt dengan lamp efficiency : 69 lumen / watt (lm/w), cool day light $6500 \mathrm{~K}$

Dengan menggunakan rumus:

$\mathrm{N}$

$$
\begin{aligned}
& =\frac{\mathrm{E} \times \mathrm{L} \times \mathrm{W}}{\emptyset \times \mathrm{LLF} \times \mathrm{CU} \times \mathrm{n}} \\
& =\frac{\mathrm{E} \times \mathrm{A}}{\emptyset \times \operatorname{LLF} \times \mathrm{CU} \times \mathrm{n}}
\end{aligned}
$$


Dimana ,
$\mathrm{A}=\mathrm{L} \mathrm{xw}$ (luas)
$\varnothing \quad=$ total lumen yang dihasilkan per 1 lampu
$\mathrm{Cu}=$ coefisien utility $(0,5-0,7)$
LLF $=$ Faktor kehilangan cahaya $(0,7-0,8)$
$\mathrm{n} \quad=$ Jumlah lampu pada 1 titik

- Untuk $\mathrm{E}=250$ lux ( ruang kelas)

$$
\begin{aligned}
\mathrm{N} & =\frac{\mathrm{E} \times \mathrm{L} \times \mathrm{W}}{\emptyset \times \mathrm{LLF} \times \mathrm{CU} \times \mathrm{n}} \\
& =\frac{\mathrm{E \times A}}{\mathrm{P} \times 69 \times 0,8 \times 0,7 \times \mathrm{n}} \\
& =\frac{250 \times \mathrm{A}}{\mathrm{P} \times 69 \times 0,8 \times 0,7 \times \mathrm{n}} \\
& =\frac{6,5 \mathrm{~A}}{\mathrm{P} \times \mathrm{n}} \\
& =\frac{7 \mathrm{~A}}{\mathrm{P} \times \mathrm{n}}
\end{aligned}
$$

Dengan perhitungan yang sama dapat ditentukan nilai k berdasarkan standar lux yang ada sehingga didapat Rumus sederhana untuk menentukan jumlah titik pada ruangan:

$$
\begin{aligned}
\mathrm{N}=\frac{\mathrm{kA}}{\mathrm{P} \times \mathrm{n}} \quad \text { dimana }, \text { untuk } \mathrm{k} & =7,8,9 \text { untuk kuat cahaya }<500 \\
\mathrm{k} & =13,20 \text { untuk kuat cahaya }>500
\end{aligned}
$$

Dengan menggunakan rumus diatas jika di terapkan di ruang 912 maka di dapat titik lampu dan kuat cahaya sebagai berikut :

$>$ Ruang 912 jika menggunakan $\mathrm{k}=7$

Diketahui :

Panjang Ruangan : 10,2 m

Lebar Ruangan : $6,45 \mathrm{~m}$

Luas Ruangan (A) $\quad: 65,79 \mathrm{~m}^{2}$

Lampu yang di gunakan:

Merk Philips, Type : TL-D 36 watt, $\mathrm{n}=2$

$$
\begin{aligned}
\mathrm{N} & =\frac{\mathrm{kA}}{\mathrm{P} \times \mathrm{n}} \\
& =\frac{7 \mathrm{~A}}{\mathrm{P} \times \mathrm{n}} \\
& =\frac{7 \times 65,79}{36 \times 2} \\
& =6 \mathrm{titik}
\end{aligned}
$$

Sehingga kuat penerangan nya sebagai berikut :

$$
\begin{aligned}
& \varnothing=\mathrm{P} \times \mathrm{L} / \mathrm{P} \\
& =1 \text { (watt) } \sim 69 \frac{L \text { (lumen })}{w(\text { watt })} \\
& =36 \text { watt } \times 69 \frac{L \text { (lumen })}{w \text { (watt })} \\
& =2484 \text { lumen } \\
& \mathrm{E}=\frac{\mathrm{N} \times \emptyset \times \mathrm{LLF} \times \mathrm{CU} \times \mathrm{n}}{\mathrm{L} \times \mathrm{W}} \\
& =\frac{6 \times 2484 \times 0,8 \times 0,7 \times 2}{65,79}=253 \mathrm{lux}
\end{aligned}
$$


Dengan menggunakan analisis geometri persegi maka jarak antar armatur sebagai berikut : Untuk menentukan jarak antar armatur :

$\begin{array}{llll}\text { Jarak antar armatur }\left(\mathrm{J}_{\mathrm{ALx}}\right) & =\frac{x}{L x} & =\frac{10,2 \mathrm{~m}}{3} & =3,4 \mathrm{~m} \\ \text { Jarak antar armatur }\left(\mathrm{J}_{\mathrm{ALy}}\right) & =\frac{y}{L y} & =\frac{6,45 \mathrm{~m}}{2} & =3,2 \mathrm{~m}\end{array}$

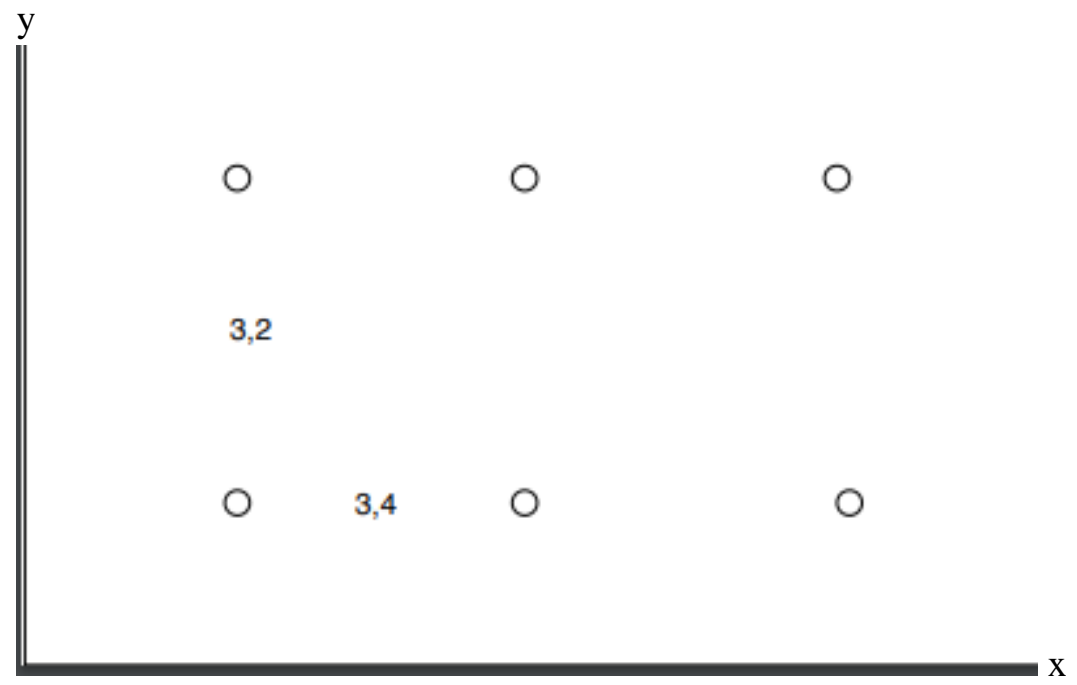

Gambar 4. Gambar Jarak Armatur

\subsection{Menghitung Kuat Penerangan Pada Ruang 912}

Dalam perhitungan penerangan di ruang perkuliahan ada beberapa hal yang harus diperhatikan:

\section{Parameter}

Panjang Ruangan

Lebar Ruangan

Luas Ruangan

Tinggi dari falpon ke lantai (h)

Tinggi dari flapon ke meja

Kuat cahaya Eb SNI

\section{Satuan}

$1020 \mathrm{~cm}$

$645 \mathrm{~cm}$

$657900 \mathrm{~cm}^{2}$

$270 \mathrm{~cm}$

$76 \mathrm{~cm}$

$250 \operatorname{lux}$

Lampu yang di gunakan:

Merk Philips, Type : TL-D 36 watt dengan lamp efficiency : 69 lumen / watt (lm/w), cool day light $6500 \mathrm{~K}$.

Kondisi eksisting penggunaan lampu di ruang kuliah 912 yaitu 12 titik armatur ( 1 armatur terdiri dari 2 lampu) menggunakan lampu jenis TL- D 36 watt.

Kondisi bila seluruh lampu terpasang di ruang 912 jenis TLD $36 \mathrm{w}$ dengan lamp efficiency $=69$ lumen / watt.

jumlah seluruh lampu yang terpasang yaitu $(\mathrm{N}$ x $\mathrm{n}=12$ armatur $\mathrm{x} 2=24$ lampu 


$$
\begin{aligned}
\varnothing & =\mathrm{P} \times \mathrm{L} / \mathrm{P} \\
& =1(\text { watt }) \sim 69 \frac{L(\text { lumen })}{w(\text { watt })} \\
& =36 \text { watt } \times 69 \frac{L(\text { lumen })}{w(\text { watt })} \\
& =2484 \text { lumen } \\
\mathrm{E} \quad & =\frac{N \times \varnothing \times L L F \times C U \times n}{L \times W} \\
& =\frac{12 \times 2 \times 2484 \times 0,8 \times 0,7}{10,4 \times 6,45} \\
& =498 \operatorname{lux}
\end{aligned}
$$

Dari hasil perhitungan didapat untuk kondisi eksisting dengan 12 titik x 2 lampu TLD 36 watt di ruang 912 maka kuat cahaya yang didapat sebesar 498 lux. Hal ini menyebabkan pemborosan pada penerangan karena untuk penerangan ruang kelas menurut SNI 03-6197-2000 sebesar 250 lux. Sehingga STT PLN mengambil langkah untuk melakukan penghematan dengan cara melepaskan 1 lampu per titik. Dengan demikian jumlah lampu yang terpasang saat ini berjumlah 12 .

Berikut perhitungan kuat cahaya menggunakan 12 lampu di ruang 912 dengan kapasitas Kondisi bila seluruh lampu terpasang di ruang 912 jenis TLD $36 \mathrm{w}$ dengan lamp efficiency $=69$ lumen $/$ watt.

$$
\begin{aligned}
\mathrm{E} & =\frac{\mathrm{N} \times \emptyset \times \mathrm{LLF} \times \mathrm{CU} \times \mathrm{n}}{\mathrm{L} \times \mathrm{W}} \\
& =\frac{12 \times 1 \times 2484 \times 0,8 \times 0,7}{10,4 \times 6,45} \\
& =249 \mathrm{lux}
\end{aligned}
$$

Dari perhitungan dengan menggunakan 12 titik ldengan 12 lampu didapat nilai kuat cahaya sebesar 249 lux, seharusnya sudah memenuhi standar ruang kelas, menurut SNI 036197-2000 (penerangan untuk ruang kelas sebesar 250 lux). akan tetapi armatur yang di gunakan terlalu banyak dari estetika ruangan kurang baik selain itu pemborosan untuk biaya armatur. Karena dari perhitungan yang sederhana dengan luas ruangan yang sama cukup dengan menggunakan 6 titik armatur saja dengan jumlah lampu 12 (1 armatur terdapat 2 lampu) sudah memenuhi standar nasional Indonesia yang ditentukan untuk ruang kelas dengan meggunakan analisa geometri persegi didapat jarak antar armatur 3,4 untuk di panjang dan 3,2 m untuk di lebar.

Untuk hasil pengukuran langsung di ruang 912 kuat cahaya yang dihasilkan 245 lux, hasil pengukuran dan perhitungan berbeda kemungkinan di sebabkan oleh umur dan pemeliharaan lampu.

\subsection{Menghitung Kebutuhan Daya di ruang perkuliahan 912}

Perhitungan ini dilakukan untuk mengetahui seberapa besar energi dan biaya pemakaian listrik untuk menghasilkan pencahayaan di ruang perkuliahan 912 dengan diketahui lampu yang di pakai yaitu Philips tipe TL-D 36watt dengan asumsi pemakaian listrik 8 jam perhari untuk ruang perkuliahan selama 25 hari. Pada kondisi eksisting jumlah lampu yang di gunakan 12 lampu. Dan untuk harga rupiah/kwh $=1.433,25$

a) Daya dan energi yang di gunakan pada kondisi eksisting 24 lampu full dalam ruangan

$$
P=24 \times 36
$$




$$
\begin{aligned}
& =864 \text { watt } \\
\mathrm{W} & =\mathrm{P} \times \mathrm{t} \times \text { Hari } \\
& =864 \times 12 \times 25 \\
& =259.200 \mathrm{Wh}=259,2 \mathrm{kWh} \\
\text { Biaya Listrik } & =\text { Energi listrik } \times \text { biaya per } \mathrm{kWh} \\
& =259,2 \times 1.433,25 \\
& =371.498,4
\end{aligned}
$$

b) Daya dan energi yang di gunakan pada kondisi eksisting 12 lampu

$$
\begin{aligned}
\mathrm{P} & =12 \times 36 \\
& =432 \text { watt } \\
\mathrm{W} & =\mathrm{P} \times \mathrm{t} \times \text { Hari } \\
& =432 \times 12 \times 25 \\
& =129.600 \mathrm{Wh}=129,6 \mathrm{kWh}
\end{aligned}
$$

Biaya Listrik = Energi listrik $\mathrm{x}$ biaya per $\mathrm{kWh}$

$$
\begin{aligned}
& =129,6 \times 1.433,25 \\
& =\operatorname{Rp} \cdot 185.749,2
\end{aligned}
$$

\subsection{Total kebutuhan energi berdasarkan titik lampu yang optimum}

Daya dan energi yang di gunakan pada kondisi 6 titik lampu dalam ruangan dengan melihat penghematan jumlah titik lampu

- Daya dan energi yang di gunakan pada kondisi 12 lampu dalam ruangan dengan melihat penghematan jumlah titik lampu pada perhitungan (4.5)

$$
\begin{aligned}
\mathrm{P} & =12 \times 36 \\
\mathrm{~W} & =432 \mathrm{watt} \\
& =\mathrm{P} \times \mathrm{t} \times \text { Hari } \\
& =432 \times 12 \times 25 \\
& =129.600 \mathrm{Wh}=129,6 \mathrm{kWh} \\
& =\text { Energi listrik } \times \text { biaya per kWh } \\
& =129,6 \times 1.433,25 \\
& =185.749
\end{aligned}
$$

Dari hasil perhitungan diatas dengan kondisi 12 titik dengan 24 lampu yang terpasang di ruang 912 energi yang di pakai selama 25 hari sebesar $259,2 \mathrm{kWh}$ dan besar biaya yang dikeluarkan selama 
25 hari sebesar Rp.371.498,4. Tetapi ketika di hitung dengan perhitungan untuk mendapatkan jumlah titik lampu didalam ruang 912 diperoleh jumlah 6 titik lampu atau aramatur dengan 12 lampu. Energi yang dipakai sebesar 129,6 kWh biaya yang dikeluarkan sebesar Rp.185.749,2 sehingga terjadi penghematan diruang 912 setengah dari kondisi eksisting selain adanya penghematan titik lampu terdapat juga penghematan pemakaian listrik.

\section{KESIMPULAN}

- Dalam studi kasus penerangan di Gedung Sekolah Tinggi Teknik PLN dapat disimpulkan bahwa di ruang gedung tersebut rata-rata di bawah standar nasional Indonesia (SNI) ketika pencahaan nya hanya memakai lampu saja.

- Untuk penerangan di atas SNI dikarenakan adanya bantuan sinar matahari.

- Untuk perhitungan jarak antar armatur dengan menggunakan analisis metode geometri persegi didapat 3,4meter dan 3,2meter sedangkan aktualnya 2,4 m dan 1,2 m. Sehingga mengakibatkan pemborosan dalam hal pemasangan armatur di dalam ruang kelas.

- Untuk perhitungan titik lampu di dapat 6 titik lampu untuk memasang armatur sedangkan aktualnya 12 titik lampu sehingga mengakibatkan pemborosan armatur. 1 armatur $=300.000$ (harga pasar) x $6=$ Rp.1800.000, jika menggunakan 6 titik armatur dapat menghemat biaya Rp 1.800.000.

- Rumus praktis untuk menentukan titik armatur dan jarak antar armatur bisa menggunakan :

- $\mathrm{N}=\frac{\mathrm{kA}}{\mathrm{P} \times \mathrm{n}}$ dimana, untuk $\mathrm{k}=7,8,9$ untuk kuat cahaya $<500$

- $\mathrm{k}=13,20$ untuk kuat cahaya $>500$

- Jarak antar armatur $\left(\mathrm{J}_{\mathrm{ALx}}\right) \quad=\frac{x}{L x}$

- Jarak antar armatur $\left(\mathrm{J}_{\mathrm{ALy}}\right) \quad=\frac{y}{L y}$

\section{DAFTAR PUSTAKA}

[1] Z. Atmam, "Analisis Intensitas Cahaya Pencahayaan Dan Penggunaan Energi Listrik di Laboratorium Komputer Sekolah Dasar Negeri 150 Pekanbaru, Jurusan Teknik elektro, Fakultas Teknik, Universitas Lancang Kuning".

[2] A. M. M. d. Syahrul, "Analisis Pencahayaan Pada Ruangan di Gedung Program Pascasarjana UNM Makassar, Fakultas Teknik UNM Makassar".

[3] S. Kurniasih, "Optimasi Sistem Pencahayaan Pada Ruang Kelas Universitas Budi Luhur Program Studi Teknik Arsitektur, Fakultas Teknik , Universitas Budi Luhur".

[4] B. S. Nasional, "Standar Nasional Indonesia Tentang Tata Cara Pencahayaan Buatan Pada Bangunan Gedung (SNI 036197)". 2000. 